\title{
Implementation and evaluation of community-based drop-in centres for breastfeeding support in Victoria, Australia
}

Rhian L. Cramer ${ }^{1,2^{*}}$, Helen L. McLachlan ${ }^{1,3}$, Touran Shafiei ${ }^{1}$, Lisa H. Amir ${ }^{1}$, Meabh Cullinane ${ }^{1}$, Rhonda Small ${ }^{1,4}$ and Della A. Forster ${ }^{1,5}$

\begin{abstract}
Background: While Australia has high breastfeeding initiation, there is a sharp decline in the first weeks postpartum and this continues throughout the first year. Supporting breastfeeding In Local Communities (SILC) was a three-arm cluster randomised controlled trial to determine whether early home-based breastfeeding support by a maternal and child health nurse (SILC-MCHN), with or without access to a community-based breastfeeding drop-in centre, increased the proportion of infants receiving any breast milk at three, four and six months. The trial was conducted in ten Local Government Areas (LGAs) in Victoria, Australia.

The primary aim of this paper is to describe the three drop-in centres established during the trial; and the profile of women who accessed them. The secondary aim is to explore the views and experiences of the drop-in centre staff, and the challenges faced in establishing and maintaining a breastfeeding drop-in centre in the community.
\end{abstract}

Methods: Evaluation of the three LGAs with drop-in centres was multifaceted and included observational visits and field notes; data collected from attendance log books from each drop-in centre; a written survey and focus groups with maternal and child health $(\mathrm{MCH})$ nurses who ran the drop-in centres; and semi-structured interviews with $\mathrm{MCH}$ coordinators of the participating LGAs.

Results: The three LGAs developed and ran different models of breastfeeding drop-in centres. They reported challenges in finding convenient, accessible locations. Overall, attendance was lower than expected, with an average of only one attendee per session. Two global themes were identified regarding staff views: implementation challenges, encompassing finding accessible, available space, recruiting volunteers to provide peer support, and frustration when women did not attend; and the work of SILC-MCHNs, including themes of satisfying and rewarding work, juggling roles, and benefits to women, babies and the community.

Conclusion: Providing community-based breastfeeding support was satisfying for the drop-in centre staff but proved difficult to implement, reflected by the lower than anticipated attendances at all of the drop-in centres. Interventions to increase breastfeeding in complex community settings require sufficient time to build partnerships with the existing services and the target population; to understand when and how to offer interventions for optimum benefit.

Trial registration: Australian New Zealand Clinical Trials Registry ACTRN12611000898954.

Keywords: Breastfeeding, Breastfeeding support, Breastfeeding promotion, Drop-in centre, Outpatient service, Community health services, primary health care, preventative health care

\footnotetext{
* Correspondence: R.cramer@federation.edu.au

'Judith Lumley Centre (formerly Mother and Child Health Research), La

Trobe University, 215 Franklin St, Melbourne, VIC 3000, Australia

${ }^{2}$ School of Nursing, Midwifery and Healthcare, Federation University Australia,

University Drive, Mount Helen, Ballarat, VIC 3350, Australia

Full list of author information is available at the end of the article
} 


\section{Background}

Australia has a high rate of breastfeeding initiation, with approximately $96 \%$ of women breastfeeding at least once whilst in hospital [1]. However, there is a sharp decline in breastfeeding rates in the first weeks after birth and the decline continues throughout the first year [1, 2]. There is also a widening gap between high and low socioeconomic populations, with infants in poorer social circumstances less likely to receive breast milk [2]. In Victoria, Australia, breastfeeding rates vary widely between Local Government Areas (LGAs), ranging from $29 \%$ to $77 \%$ of infants receiving any breast milk at 6 months [3, 4].

We undertook a trial to introduce and evaluate an intervention aimed at increasing breastfeeding rates by providing community-based breastfeeding support in the early postpartum period $[5,6]$. Supporting breastfeeding In Local Communities (SILC), was a three-arm cluster randomised controlled trial (RCT), including ten local government areas (LGAs) in the state of Victoria, with LGAs as the unit of randomisation [5]. LGAs that had a lower than average rate of women providing any breast milk to their infants at discharge from hospital, with greater than 450 births per year, and that agreed to participate, were randomly allocated to one of three trial arms: 1) standard care (comparison arm); 2) home-based breastfeeding support (home visits, HV); or 3) homebased breastfeeding support plus access to a communitybased breastfeeding drop-in centre (HV plus drop-in centre). Maternal and Child Health Nurses (MCHNs) were recruited by each LGA (called SILC-MCHNs) to provide the home-based breastfeeding support (all SILC$\mathrm{MCHNs}$ ) as well as to staff the community-based breastfeeding drop-in centres (only SILC-MCHNs in the HV plus drop-in centre trial arm). Further details of the recruitment and randomisation process can be found in the SILC trial protocol [5].

The intervention was pragmatically designed so that if such an intervention did increase breastfeeding rates then it would be able to be readily incorporated into practice in Victoria. It was important during this trial not only to investigate if the interventions resulted in a clinically important difference in breastfeeding rates at four and six months, but also to test the feasibility of implementing the interventions. The home-based breastfeeding support was designed for women at risk of ceasing breastfeeding before six months and the trial protocol guided LGAs in how to assess women for this visit [5].

Overall the trial found no difference in breastfeeding outcomes between standard $\mathrm{MCH}$ care and either of the intervention trial arms [6]. Given the findings, process evaluation measures to ascertain whether the interventions were implemented as planned are crucial in explaining and understanding the trial outcome. Data collection for the process evaluation included measuring adherence to the SILC protocols, measurements of intervention exposure, and exploring the views and experiences of the SILC-MCHNs and the $\mathrm{MCH}$ coordinators at each of the six intervention LGAs. A description of the content of the SILC-MCHN home visits has been published separately [7].

The Victorian Government Department of Education and Early Childhood Development (DEECD) commissioned the SILC trial with the intent to design, implement and evaluate innovative breastfeeding interventions to improve breastfeeding rates in the state of Victoria. Drop-in centres offering breastfeeding support within community settings was one innovation strongly supported by MCHNs [8], as it was felt they provided the opportunity to provide not only breastfeeding support, but also social support and education, which is widely discussed in the breastfeeding literature as a key factor in breastfeeding success $[9,10]$.

There have been few evaluations of breastfeeding drop-in centres published; even less focussed on drop-in centres with multifaceted professional, communitybased breastfeeding support. The systematic reviews that reported on community support for breastfeeding were about the provision of peer support [11-13]. Of those papers that did describe and/or evaluate professional breastfeeding support services, the majority were located within or adjacent to hospitals [14-16]. A small number of publications were identified that described informal drop-in centres for breastfeeding mothers to be able to access within their own community [17-20]. Table 1 shows all identified studies of breastfeeding drop-in centres and gives an overview of each study. Breastfeeding drop-in centres were effective in improving women's satisfaction with their breastfeeding experience [15, 18, 20], and authors reported increased breastfeeding duration $[18,21]$ to four $[15]$ and/or six months $[15,17]$. One evaluation of existing drop-in services compared the breastfeeding rates of drop-in centre attendees to the population data for the local area [15]. Two studies found that women motivated enough to seek breastfeeding support, such as those women seeking support at a drop-in centre, were more likely to be determined to breastfeed and overcome any barriers they encountered $[22,23]$. There is strong evidence that motivation to breastfeed is one of the most important predictors of breastfeeding success $[22,23]$, so comparison to the population data may be misleading and therefore results from these studies need to be interpreted with caution.

Community based drop-in services have been successfully established in many other areas of health and human services. These include services targeting sexual health [24-27]; homelessness [28, 29]; youth services 


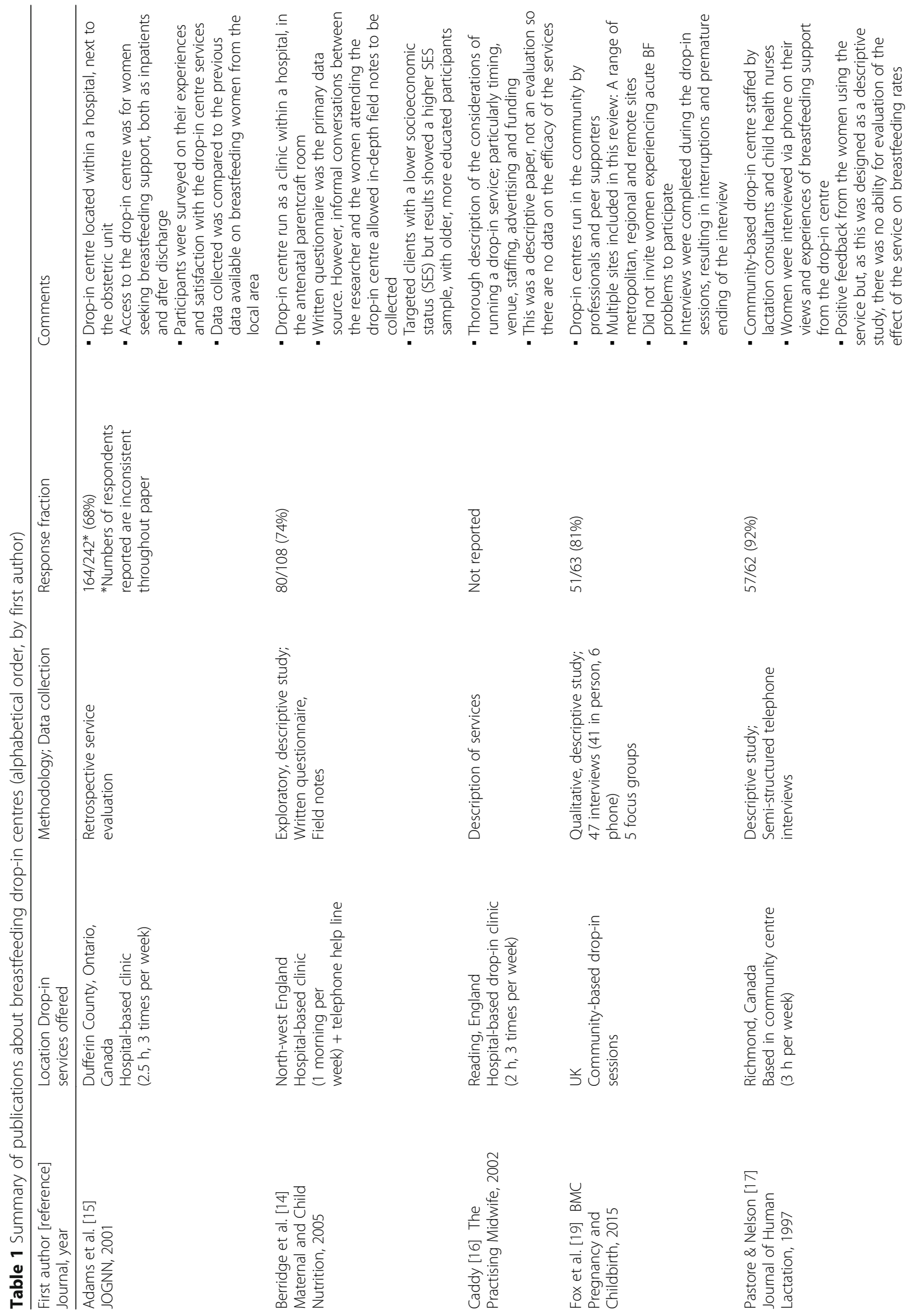




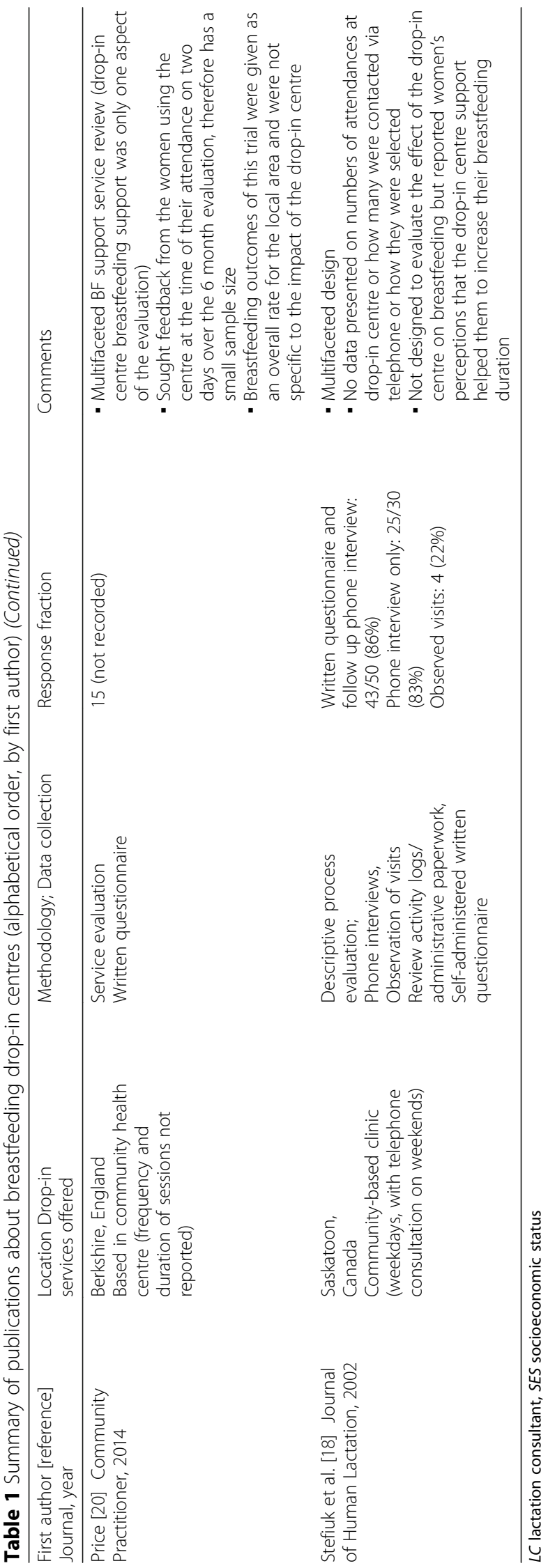


[26, 28, 30-33]; eating disorders [34]; smoking cessation $[35,36]$; needle exchange programs and safe injecting rooms [37]. While the services differ greatly in their target group and purpose, the integral components of service provision within community settings are social support [14, 15, 24, 29], community building [30], isolation reduction $[14,29,30]$ and referral to other available services within the community $[17,24,25,29,30]$.

In Victoria, Australia, there are approximately 74,000 births per year [38]. Universal care for mothers and infants is provided by MCHNs, who are skilled clinicians with qualifications in nursing, midwifery, and maternal and child health. Irrespective of a woman's locality or maternity care provider, once discharged from hospital, every mother is entitled to $\mathrm{MCH}$ care, free of charge. A home visit is scheduled within the first two weeks of birth whenever possible, then pre-specified consultations at the local $\mathrm{MCH}$ centres are scheduled based on childhood milestones. These visits are known as 'Key Ages and Stages' consultations. This support involves ten visits from birth until the child reaches three and a half years of age and the aim is that the health of both mother and child are addressed [39].

The primary aim of this paper is to describe the SILC drop-in centres, how they were established and maintained, and the profile of women who accessed the drop-in services. The secondary aim is to explore the views and experiences of the SILC-MCHNs and $\mathrm{MCH}$ coordinators; the perceived benefits of the service; and the challenges faced in establishing and maintaining a breastfeeding drop-in centre in the community.

\section{Methods}

The study used qualitative and quantitative data from surveys, focus groups, interviews, drop-in centre log books and visitors' comment books, and SILC-MCHN diaries. Each data source is described below. The SILC intervention period was between September 2012 and March 2013, and data for this project were collected between September 2012 and January 2014.

Each LGA was allocated a proportion of the available SILC-MCHN equivalent full time (EFT) funding determined by the number of births (with funding provided by the State government). The three LGAs randomised to having a drop-in centre could allocate these funds to staff the centres to best suit their local community. Each LGA decided on which days and for how many hours each drop-in centre would run, within their allocated funding. Each LGA was given the scope to develop the drop-in services with their own community's needs in mind, and the location was determined by the LGA. Consequently, each of the LGAs proposed, developed and ultimately ran different styles of drop-in centre. Our intention was for the services to be similar to Baby Cafés in the United Kingdom [19, 40], in that they should be accessible to women; close to public transport; welcoming spaces suitable for new mothers and babies; provide privacy for feeding; and provide access to change tables, toilets and drink facilities. Our aim was that both professional and peer support would be available so that women would be able to discuss breastfeeding issues or concerns with the SILC-MCHN in the centre and at the same time meet other mothers, so that women could learn from each other. LGAs advertised and promoted the drop-in centres within their LGA. A two month runin period prior to the official trial period facilitated the set-up of the drop-in centres and commencement of service provision in an effort to identify and resolve any challenges encountered. It also gave time to raise community awareness of the drop-in centres.

\section{Drop-in centre attendance and functioning}

Observational visits were conducted at drop-in centres in each of the three LGAs by RLC in March 2013. Informal discussions took place with the SILC-MCHN present regarding opening hours of the drop-in centres, choice of location, and amenities available and detailed field notes were kept. Also discussed was the promotion of the drop-in centres and any advertising conducted to inform women of the drop-in centres available. Photographs of the location and facilities were taken. In the event there were any staff or participants to be included, written consent was obtained prior to the photograph being taken.

During the time the SILC interventions were in place, SILC-MCHNs were asked to maintain tools that helped the research team understand intervention compliance, including log books to record women's visits to the drop-in centres, visitors' comment books and SILC$\mathrm{MCHN}$ diaries. Items included in the log book were the date of the visit, infant age, maternal parity, reason for attending the service, and whether this was the first visit to the centre. Diaries were provided for SILC-MCHNs to record their reflections and experiences of running the drop-in centres. They were encouraged to complete one entry per drop-in session to provide a record of their views and experiences of the drop-in centres as they were implemented and became established and then, if applicable, when the service was closed. Visitors' comment books were provided at each of the drop-in centres and SILC-MCHNs were encouraged to have the women attending the service complete entries on their thoughts and experiences of the drop-in centre.

\section{Exploring SILC-MCHNs views: Focus group and survey}

SILC-MCHNs' views and experiences of the drop-in centres were sought via a focus group and a short survey. We used the two approaches because we felt some 
SILC-MCHNs may not be comfortable reporting challenges they may have faced in the focus group context given they knew the other participants, and that the workplaces and LGAs may be identifiable.

The focus group was held in the final month of the intervention (March 2013), at a scheduled SILC-MCHN workshop. SILC-MCHNs could choose to stay on after the workshop and participate in the focus group. The focus group schedule was developed specifically for the study. Topic areas included SILC-MCHNs' experiences of participating in the SILC trial; the role of the SILCMCHN; positive aspects of the intervention; and any challenges faced.

Similar topic areas informed the questions in the written survey, which was distributed after the focus group discussion. The survey included demographic characteristics; Likert-type scales exploring SILC-MCHNs' ability to work autonomously; satisfaction with support received during the trial; confidence in the SILC-MCHN role; perceived sustainability of the drop-in centres; and open-ended questions. The final survey included 26 questions and took 10 to $15 \mathrm{~min}$ to complete.

Piloting of the SILC-MCHN survey was undertaken by colleagues from the Judith Lumley Centre with experience in maternal and child health, resulting in minor changes to formatting. The focus group schedule was also piloted by colleagues with experience in maternal and child health. As a result, a question was added to explore whether the role of SILC-MCHN changed over the trial period.

Written consent was obtained from the SILC-MCHNs prior to the focus group, which was audio-recorded and transcribed verbatim. Return of the survey was taken as consent for that component.

\section{Exploring the views of $\mathrm{MCH}$ coordinators: Semi-structured interviews}

The views and experiences of $\mathrm{MCH}$ coordinators who were involved in establishing the drop-in centres were explored via semi-structured face-to-face interviews. The interviews were conducted at a location and time convenient to the $\mathrm{MCH}$ coordinators between March and May 2013. The interviews explored the implementation of the SILC interventions within the universal $\mathrm{MCH}$ service, the perceived benefits of the interventions, the challenges faced during the trial period, and any other issues the $\mathrm{MCH}$ coordinator wished to discuss. Following written consent, the $\mathrm{MCH}$ coordinator interviews were audio-recorded.

\section{Data management and analysis}

All sources of data were de-identified. Unique identifying numbers were allocated to LGAs and pseudonyms assigned to individuals. The three LGAs are referred to as $\mathrm{A}, \mathrm{B}$ and $\mathrm{C}$ in this paper.

Audio files from the SILC-MCHNs' focus group and the $\mathrm{MCH}$ coordinator interviews were transcribed verbatim. Open-ended responses from the SILC-MCHNs' survey were entered into an Access database verbatim. Inductive thematic analysis was undertaken: first, data immersion was undertaken, where the transcripts were read and re-read to gain an understanding of the data, then data were coded. 'Basic themes' with similar responses were grouped together into 'organisational' themes [41, 42]. From these groups, key 'global' themes were identified $[41,42]$. Analysis was undertaken independently by RLC and HLM then compared to ensure validity of emergent themes, with any differences in interpretation of data discussed and resolved.

Quantitative data from the SILC-MCHN survey were entered onto an Access database and analysed using Stata version 11 [43]. The SILC-MCHNs' diaries and visitors' comment books were poorly completed. From 326 drop-in sessions, there were 54 SILC-MCHN diary entries completed, of which 47 were completed by one SILC-MCHN. There were 22 entries in the visitors' comments books in total. As a result, these data were not analysed further, and are not included in this paper.

\section{Results}

\section{Description of drop-in centres}

LGA A is located in regional Victoria, with 1300 births registered in the LGA per year [44]. At the time the SILC study commenced, the LGA had been awarded government funding to establish a service aimed at parenting support more broadly, not solely focussed on breastfeeding, and a local decision was made to combine this funding with the allocated SILC trial funds and establish a parenting drop-in centre (Fig. 1). The drop-in centre was set up in a local shopping mall and was open weekdays between 10 am and $2 \mathrm{pm}$. It was primarily run by volunteers, who received training in peer counselling. The SILC trial funding allowed a SILC-MCHN to be present between 11 am and 1 pm daily to address any issues that required specialist lactation consultant input. The drop-in centre was promoted within the local hospitals, with flyers distributed by midwives in the maternity units, neonatal special care units and domiciliary services. These flyers were also available in the maternal and child health centres and a Facebook page was created to promote the service. LGA A was the only LGA able to recruit and maintain volunteer staff.

LGA B is located in rural Victoria and has approximately 560 births per year registered in the LGA [44]. One SILC-MCHN was employed to run the drop-in sessions for two to three hours, three times per week. Three different locations were used for this drop-in 


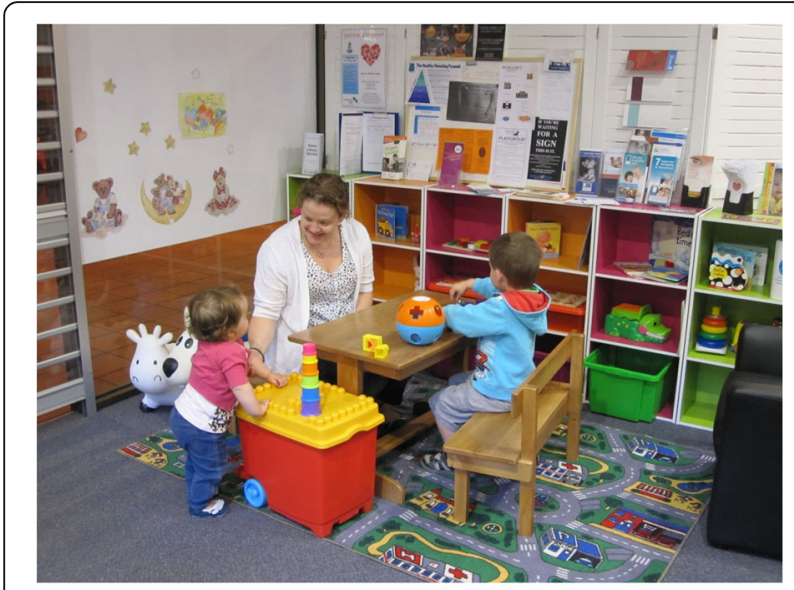

Fig. 1 Local Government Area A: Parenting drop-in centre

service, in different country towns within the LGA two in local cafes, one in a local $\mathrm{MCH}$ centre. The two cafes set up an area for breastfeeding mothers to gather and discuss their breastfeeding experiences and any concerns or issues they were having. Posters were displayed during these sessions to make the drop-in sessions visible to the public, and breastfeeding information was available. One of the cafes had the ability to close off a private area for breastfeeding as needed (Fig. 2). The other cafe location did not have this option. The area allocated for this drop-in centre was in the front window of the cafe, which faced out onto the street (Fig. 3). Promotion of the drop-in centres was via flyers in $\mathrm{MCH}$ centres, general practice clinics, hospitals, kindergartens and child care centres. There was an article in the local newspaper and the drop-in service was advertised on local radio. Information was also provided on the LGA website. LGA B attempted to recruit volunteers through existing community breastfeeding support agencies, such

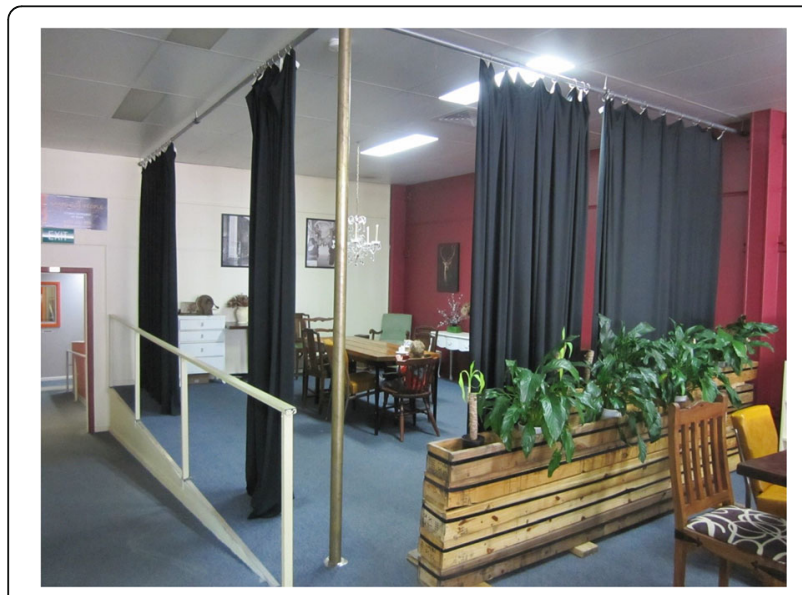

Fig. 2 Local Government Area B: Drop-in centre in local café in town 2

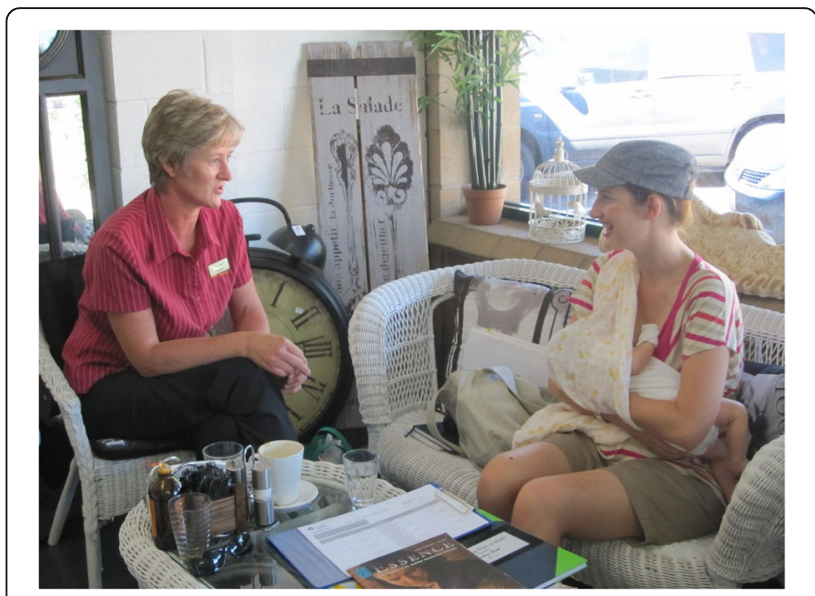

Fig. 3 Local Government Area B: Drop-in centre in local café in town 1

as the Australian Breastfeeding Association, but this was unsuccessful.

LGA C was the largest LGA in this trial arm, located in metropolitan Melbourne, with approximately 2700 births per year registered in the LGA [44]. The drop-in centres were located in $\mathrm{MCH}$ centres (Fig. 4) in three different suburbs within the LGA, to increase the access across the large geographical area the LGA covered. Sessions lasting three and a half to five hours per week were held three times per week, one at each location. To promote the drop-in sessions, flyers were distributed by the LGA MCHNs during the first Key Ages and Stages home visit. An article was also printed in the local newspaper. Social media (predominantly Facebook) was used by local mothers to promote the drop-in centres. LGA C also attempted to recruit volunteers through existing community breastfeeding support agencies but they too were unsuccessful.

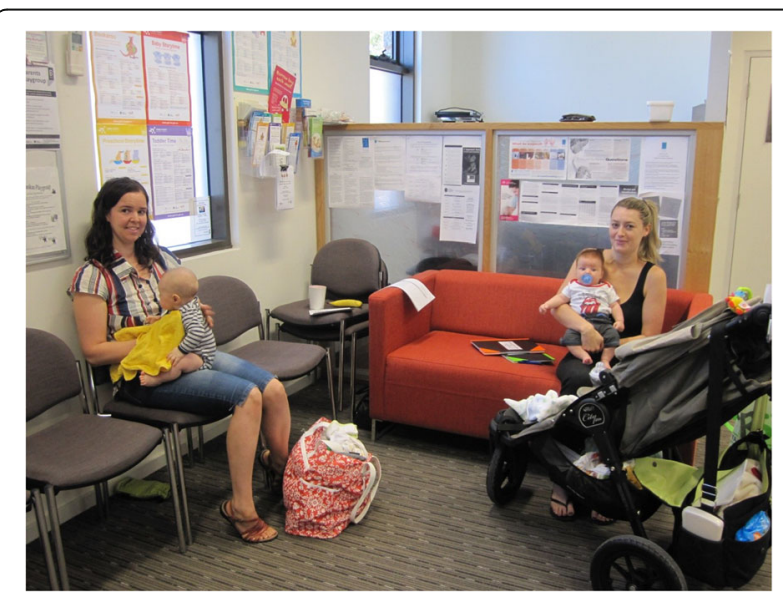

Fig. 4 Local Government Area C: Drop-in centre in Maternal and Child Health centre 


\section{Drop-in centre attendance}

Table 2 describes drop-in centre activity in each LGA including the number of drop-in sessions, and the number of attendances for breastfeeding support and/or information in each LGA during the trial period. Because women could attend the drop-in centres as often as they wished, the number of attendances includes women who visited on multiple occasions. Overall, the drop-in centres were not well attended; across the LGAs, there was an average of one attendance per session for breastfeeding support/information.

The median age of infants when women attended the drop-in centres for support with a breastfeeding issue was 11 weeks in LGA A, four weeks in LGA B, and five weeks in LGA C. Over half of the mothers attending were first time mothers across all LGAs.

Reasons women attended the drop-in centres are outlined in Table 3. Seeking breastfeeding support and/or having breastfeeding issues were reported as reasons for drop-in centre visits in the majority of attendances in LGA B and LGA C. However, only $15 \%$ of attendees in LGA A (the parenting centre) reported these as the reason for attendance. Other reasons included to meet or help other mothers, to feed their baby, or for parenting information.

\section{SILC-MCHNs' and MCH coordinators' views and experiences of the drop-in centres}

Seven SILC-MCHNs were employed to run the drop-in centres and all completed the written survey; six following the SILC-MCHN workshop held during the last weeks of the trial period and one via email, as she was unable to attend the workshop. The majority were in the age group between 45 years and 64 years $(n=6)$. Six of the seven SILC-MCHNs were registered midwives and
$\mathrm{MCH}$ nurses (one SILC-MCHN no longer held her midwifery registration but was a registered $\mathrm{MCH}$ nurse); four were currently certified International Board Certified Lactation Consultants (IBCLCs); and one SILCMCHN was a previously certified IBCLC. On average the SILC-MCHNs had 17 years' experience in midwifery (ranging from 3 years to 35 years); 12 years' experience in $\mathrm{MCH}$ (ranging from 3 to 30 years); and, for those with relevant IBCLC qualifications, 14 years' experience as IBCLCs (ranging from 1 to 27 years).

Six SILC-MCHNs also participated in the focus group. Four $\mathrm{MCH}$ coordinators and managers from the three home visit plus drop-in centre LGAs were identified and invited to participate in the interviews; all consented and were interviewed between March and May 2013. Data from all sources have been combined.

Overall, the SILC-MCHNs and $\mathrm{MCH}$ coordinators described many factors that they believed had influenced the success (or not) of the drop-in centres. The practicality of setting up the drop-in centres in accessible locations and encouraging women to attend was complex. Thematic analysis identified two global themes: implementation challenges and the work of SILC$M C H N s$. Within each global theme, three organising themes were identified. Those relating to implementation of drop-in centres were: accessible, available space; recruiting volunteers to provide peer support; and frustration when women did not attend. Those relating to the work of SILC-MCHN were: satisfying and rewarding work; juggling roles; and benefits to women and babies.

\section{Implementation challenges}

Implementing the drop-in centres proved challenging for the participating LGAs. In particular, identifying an accessible and available space, recruiting volunteers to

Table 2 Drop-in sessions and attendances for breastfeeding support at SILC drop-in centres in LGAs allocated to home visit plus drop-in centre trial arm $^{\mathrm{a}}$

\begin{tabular}{|c|c|c|c|c|}
\hline Location & $\begin{array}{l}\text { LGA A } \\
\text { Regional }\end{array}$ & $\begin{array}{l}\text { LGA B } \\
\text { Rural }\end{array}$ & $\begin{array}{l}\text { LGA C } \\
\text { Metropolitan }\end{array}$ & Total \\
\hline Hours open & $\begin{array}{l}4 \mathrm{~h} / \text { day } \\
5 \text { days/week }\end{array}$ & $\begin{array}{l}2-3 \text { h/day } \\
3 \text { days/week }\end{array}$ & $\begin{array}{l}\text { 4-5 h/day } \\
3 \text { days/week }\end{array}$ & \\
\hline Total sessions open & 140 & 92 & 87 & 319 \\
\hline Number of volunteers, mean (range) & $2(0,6)$ & - & - & - \\
\hline \multicolumn{5}{|l|}{ Attendances for breastfeeding support/information } \\
\hline Attendances for breastfeeding support/information, n (\%) & $148(15)$ & $78(83)$ & $229(84)$ & 455 \\
\hline Average attendances/session & 1 & 0.8 & 2.6 & 1.4 \\
\hline Infant age (weeks):mean (SD) and median (range) & $\begin{array}{l}17(17.0) \\
11(0,100)\end{array}$ & $\begin{array}{l}8(10.3) \\
4(0,60)\end{array}$ & $\begin{array}{l}5(4.7) \\
4(0,26)\end{array}$ & $\begin{array}{l}9(12.1) \\
5(0,100)\end{array}$ \\
\hline First baby, n (\%) & $78(53)$ & $49(63)$ & $153(67)$ & $280(62)$ \\
\hline First visit, n (\%) & 99 (66) & $52(67)$ & $158(69)$ & $307(67)$ \\
\hline
\end{tabular}

Includes SILC trial run in period

SILC Supporting breastfeeding In Local Communities, LGA Local Government Area 
Table 3 Women's reasons for attending drop-in centres (data from drop-in centre log books) $^{a}$

\begin{tabular}{|c|c|c|c|c|c|c|c|c|}
\hline & \multicolumn{2}{|c|}{$\begin{array}{l}\text { LGA A } \\
n=1014\end{array}$} & \multicolumn{2}{|c|}{$\begin{array}{l}\text { LGA B } \\
n=94\end{array}$} & \multicolumn{2}{|c|}{$\begin{array}{l}\text { LGA C } \\
n=274\end{array}$} & \multicolumn{2}{|c|}{$\begin{array}{l}\text { Total } \\
n=1382\end{array}$} \\
\hline & $\bar{n}$ & $\%$ & $\bar{n}$ & $\%$ & $\bar{n}$ & $\%$ & $\bar{n}$ & $\%$ \\
\hline Breastfeeding reasons & 148 & 15 & 78 & 83 & 229 & 84 & 455 & 33 \\
\hline Breastfeeding issue & 106 & 10 & 38 & 40 & 162 & 59 & 306 & 22 \\
\hline Breastfeeding support & 126 & 12 & 61 & 65 & 81 & 30 & 268 & 19 \\
\hline \multicolumn{9}{|l|}{ Social support } \\
\hline Meet other mothers & 31 & 3 & 9 & 10 & 1 & $<1$ & 41 & 3 \\
\hline Help other mothers & 19 & 2 & 7 & 7 & 1 & $<1$ & 27 & 2 \\
\hline \multicolumn{9}{|l|}{ Parenting } \\
\hline Feed my baby ${ }^{b}$ & 412 & 41 & 5 & 5 & 14 & 5 & 431 & 31 \\
\hline Parenting information ${ }^{d}$ & 129 & 13 & - & - & - & - & - & - \\
\hline Other ${ }^{c}$ & 590 & 58 & 9 & 10 & 26 & 9 & 625 & 45 \\
\hline
\end{tabular}

aparticipants could indicate multiple options, so \% could add to $>100$

${ }^{b}$ Included both breastfeeding and formula feeding

${ }^{c}$ Reasons included using the facilities, weighing baby and having a rest

${ }^{\mathrm{d}}$ Only an available option for LGA A

LGA Local Government Area

provide peer support, and frustration when women did not attend were obstacles encountered by SILC-MCHNs and $\mathrm{MCH}$ coordinators when establishing the drop-in centres.

\section{Accessible available space}

Issues with drop-in centre location were raised by the SILC-MCHNs and MCH coordinators. This included the challenge of finding a suitable location. Two LGAs moved the location of their drop-in centre during the trial period; one moved due to poor attendance, the other changed the locations to be in a more public space.

"There were some logistical difficulties like finding a drop-in [space], finding a suitable building, arranging times.” (Olivia, MCH coordinator)

"We had one originally ... and our numbers were pretty poor... so then we moved it ... [near public transport, and now] it's near a shopping centre where people are and the numbers were much better there." (Naomi, MCH coordinator)

"We started off with [drop-in centres] at some of the [MCH] centres but we quickly moved them into cafes because we thought that was sort of a more interesting way to have a go at it ... " (Quinn, MCH coordinator)

\section{Recruiting volunteers to provide peer support}

Another challenge highlighted in the SILC-MCHN focus groups and in the $\mathrm{MCH}$ coordinator interviews was the difficulty recruiting and maintaining a volunteer workforce to offer peer support in the drop-in centres. Only one LGA was able to recruit and maintain volunteer staff.

"Obtaining and retaining volunteers is really difficult." (Kate, focus group)

"We just got nowhere . . we tried . . . we just couldn't get the volunteers. I don't know why. Maybe we didn't market it properly. [It] would have been great to have that second person." (Naomi, MCH coordinator)

\section{Frustration when women did not attend}

Most of the SILC-MCHNs reported feelings of frustration, running drop-in centres with low attendance rates, and many had sessions where no women attended. The SILC-MCHNs felt their time might have been better used in other activities but they were obliged to remain at the drop-in centre.

"At times frustrated due to lack of clients / mothers.
Very satisfied with outcomes when [mothers] did
attend." (Tracy, SILC-MCHN survey)

"Very satisfied when women attended but found the drop-in sessions a bit frustrating when no one attended and you knew that you could be utilising that time doing home visits." (Amy, SILC-MCHN survey)

One of the $\mathrm{MCH}$ coordinators acknowledged the difficulties of low attendance, but described this as one of the challenges faced by many services in smaller, rural areas. She did not consider that this diminished the value of the service to the women who did access the drop-in centres.

"It's the same with offering any service in country areas, population density is a real issue in terms of cost because you might run a group in Melbourne and have eight or ten participants, but [country towns] only have two, but it's still as valuable to those two."

(Quinn, MCH coordinator)

During the focus group discussion, the SILC-MCHNs who ran the drop-in centres offered several theories about why the drop-in centre attendances were lower than anticipated. Some believed that the women found it difficult to travel within the first few weeks and may have thought it was too difficult to go out with their new baby to seek breastfeeding support. 
"People didn't want to travel with a 7 day old baby... crying and screaming all day and you're tired and you don't want to go out." (Georgia, focus group)

Another reason SILC-MCHNs felt women may not have attended was a lack of privacy, particularly where the centres were established in a public space, which may have been confronting for new mothers seeking breastfeeding help and support. With the drop-in centre set up in the front window of a local café (as was the case in one LGA), the SILC-MCHNs considered that breastfeeding mothers may have felt very exposed, and consequently, they did not utilise the service. (The use of a cloth over the baby and the mother's breast in Fig. 3 is an example of a mother's attempt for privacy in this setting.) This was also noted by an $\mathrm{MCH}$ coordinator, who felt a cultural shift was needed before women could fully embrace breastfeeding in public places in their small community.

"We ran [drop-in centres] in cafes and that really wasn't successful. I suspect that's quite a cultural change to be part of." (Quinn, MCH coordinator)

One LGA reported having a highly culturally and linguistically diverse population, which may have impacted on women's capacity to get out of the house to seek breastfeeding support.

"I think [part of the LGA] has a lot of non-English speaking [women] and they have a lot of cultural limitations as well. Not allowed to leave [the house] for 40 days and all that sort of stuff. Or no transportation because the husband's got the car and they can't get out ... They're often isolated because their family members are [overseas] so they don't know how to ... they're too scared to get out and mix too much." (Georgia, focus group)

The SILC-MCHNs in the focus groups reported encouraging women to come to drop-in centres for reasons other than breastfeeding help and support, in order to get the women to attend. A SILC-MCHN from one LGA reported encouraging women to use the SILC drop-in centre as a 'test run' for taking a newborn out in public. Another would encourage women to bring their newborn in to be weighed, as they felt women were concerned with infant weight and more likely to attend the drop-in centres if their baby would be weighed.

"[Women] would say "oh I'm not ready to go out [with my baby]" and I would say "well this is a really safe place with a spot there. How about using it as your trial run for going out for the first time?"”

(Kate, focus group)
"You'd say "come back and get them weighed" rather than [focusing on] feeding ... because they were really worried about the weight they would come to the drop in [centre]." (Georgia, focus group)

\section{The work of SILC-MCHNs}

SILC-MCHNs reported three main factors in relation to their work during the trial period: satisfying and rewarding work; juggling roles; and benefits to women, babies and the community. The SILC-MCHNs enjoyed the work they were doing to support breastfeeding mothers and their families, but some also encountered difficulties managing workloads for their different roles.

\section{Satisfying and rewarding work}

A strong theme that came through from the focus group discussion was the satisfaction the SILC-MCHNs felt in their work. They reported feeling satisfied when they were able to help a mother feed her baby or resolve other early parenting issues, although no specific examples were mentioned.

"II really enjoyed the role and would love to see it carried on." (Tracy, SILC-MCHN survey)

"I] felt I did make a difference to how women felt about themselves and their baby - hopefully I helped to empower those few women I saw to try new ways of thinking about their feeding."

(Whitney, SILC-MCHN survey)

\section{Juggling roles}

Six of the seven SILC-MCHNs involved in running the drop-in centres were also responsible for the provision of home visits as part of the SILC trial. This presented challenges in ensuring the SILC-MCHN could physically get to the drop-in centre in time to run the sessions. This was particularly difficult in the LGAs with larger geographical areas to cover and resulted in the SILCMCHNs having to undertake complex planning around their schedules.

"Extremely challenging, depending geographically where you were going for the next visit. . Y You had to be very organised and pre-plan the day before. I always knew geographically exactly where I was going the next day and had it worked out to the minute, pretty well." (Kate, focus group)

"II] very often ate lunch in car on the way to the dropin session ... because if I'm travelling from one end of the shire to the other it's an hour driving so I could 
have a home visit in [one town] and then have to be in [another town] for the drop-in sessions so that was quite challenging." (Frances, focus group)

This challenge was acknowledged by the $\mathrm{MCH}$ coordinators, who were responsible for managing the SILC-MCHN and the universal MCH services.

"It was difficult to schedule a staff member who's doing both home visiting and staffing a drop-in . . It made her day a bit tight sometimes." (Olivia, $\mathrm{MCH}$ coordinator)

For example, one LGA introduced a strategy to alleviate the issue of the SILC-MCHN juggling roles. The SILC-MCHN ran the drop-in centre in the morning and allocated the afternoon for completing other duties. On Fridays, when the drop-in centre was open for five hours, the SILC-MCHN was rostered to facilitate the drop-in centre only, and was not allocated any additional duties, such as home visits or other routine MCHN workload.

\section{Benefits to women, babies and the community}

All the SILC-MCHNs were positive about the support they were able to provide when women did attend the drop-in centres. They also reported seeing the benefit of two or more mothers attending the drop-in centre at the same time so that they were able to talk to each other and compare experiences, and offer informal peer support.

"With other mums there the conversation flows. When you've got 2 or 3 [mothers] they're looking at other people that have similar concerns that they have." (Isobelle, focus group)

\section{"I think a lot of what we do is to assist / facilitate} women to network." (Benita, SILC-MCHN survey)

Another perceived benefit was that the community as a whole were able to be educated about breastfeeding through the availability of the drop-in centres. One LGA drop-in centre was located in a local cafe at lunchtime, so was very visible within the community, and the SILCMCHN reported that this attracted questions and interest from those coming to the cafe during the busy lunchtime period.

"I had [the drop-in centre] at a café... I was usually up the front in the windows space in the lounge area I did have a lot of people [because] it is a busy cafe, so a lot of people would ask what I was doing there ... [I] had an elderly gentleman sit with me last week who thought he better move on before they got the wrong idea!" (Frances, focus group)

\section{Discussion}

The LGAs developed and ran very different models of breastfeeding drop-in centres during the SILC trial. Overall, attendance was low, with an average of only one attendee per session. A range of complex factors impacted on the establishment of the drop-in centres and also the attendance by women. Two global themes were identified: the implementation challenges, including themes of accessible, available space, recruiting volunteers to provide peer support, and frustration when women did not attend; and the work of SILC-MCHNs, including themes of satisfying and rewarding work; juggling roles; and benefits to women, babies and the community.

Attendance rates varied greatly between and within LGAs. LGA A experienced the greatest demand for drop-in centre services during the trial, though primarily for parenting support, not specifically for breastfeeding. LGA C's attendance rates varied greatly between their three drop-in centres, highlighting the importance of location and opening hours to the success of the service. A number of other studies of breastfeeding drop-in centres and drop-in centres established for health promotion and social support activities have also reported on these issues $[16-18,24,26,29,30,45]$, i.e. the importance of the location being easily accessible $[18,24,30]$, and that the hours suit the target population, as opposed to what is convenient for the staff running the service $[16,17,24,26,29]$.

Another possible reason for the lack of attendance may be that women are increasingly seeking parenting support [46] and, by extension, infant feeding support from social networking sites. They are no longer required to leave their home to access support and advice, which can now be accessed from their smartphone, tablet or computer [46]. As women perceive this online activity as providing valuable support $[47,48]$, they may be satisfied to engage with their online communities and not feel the need to attend services like drop-in centres. Further investigation of women's experiences of breastfeeding support during the SILC trial, including the sources of breastfeeding advice and support, will be presented in a future publication [49].

One of the drop-in centres from LGA B was held in the front window of the local cafe during lunchtime. It was located in a small, country town and was very visible. Given some women's reluctance to breastfeed in public [50-52], it is possible this public location may have made women feel uncomfortable seeking breastfeeding advice and support in such a visible space. 
Due to funding-related time constraints, the drop-in centres in this study were open for nine months in terms of trial data collection, with an additional two months for the set up and run-in period. It is possible that there may have been greater attendance if the services had been able to have a longer run-in period, allowing time for them to become more established within the community. Other studies have reported that ongoing adaptability of drop-in centres and the ability to engage and partner with, and adapt to the needs of, the target population may contribute to the overall success of a service $[24,25]$. It has also been reported that establishing dropin centres takes significant time $[25,26,30,32]$. Since the completion of the SILC trial, two of the three SILC LGAs are continuing to offer breastfeeding drop-in centres, with an increase in attendance numbers $(\mathrm{MCH}$ and Immunisation Clinical Coordinator: LGA A, personal communication, 8 November 2016; Team Leader MCH: LGA C, personal communication, 15 November 2016). A representative from one LGA reports the breastfeeding drop-in centres are now considered an integral part of the care provided to women and there are plans to extend the services to four days per week (MCH coordinator: LGA C, personal communication, 8 November 2016).

\section{Strengths and limitations}

This study explored the SILC-MCHNs' and MCH coordinators' views and experiences of implementing the SILC drop-in centres. The use of multiple data sources provided an opportunity to explore what was successful and what challenges were faced from each viewpoint, enabling a multi-level evaluation of the services. All $\mathrm{MCH}$ coordinators from the drop-in centre LGAs were interviewed and all SILC-MCHNs employed on this trial completed the written survey to give their experiences and feedback. All but one SILC-MCHN also participated in the focus group discussion. The high participation rate in key evaluation activities allows a complete picture of the intervention to be ascertained and strengthens the validity of the results of this evaluation.

The SILC-MCHNs employed in SILC were selfselected, motivated and dedicated to promoting and supporting breastfeeding for their communities, and all had undertaken additional training and breastfeeding education. These results reflect the SILC-MCHN views and experiences and may not be generalisable to all MCHNs, as there are likely to be differing views about the importance of breastfeeding and how best to support new mothers with infant feeding.

\section{Conclusion}

This study explored the implementation of communitybased breastfeeding drop-in centres and evaluated the service from the views and experiences of the SILC-
MCHNs employed to run them, and from the $\mathrm{MCH}$ coordinators tasked with overseeing the drop-in centres from a management perspective. Overall, the SILCMCHNs enjoyed the work they were doing supporting breastfeeding and felt they could make a difference for women and families, but attendance was low, and getting women to attend proved difficult. It is possible that running the drop-in centres for a longer period of time may have improved attendance rates, as the centres became more integrated into, and accepted by, the community. Further research is needed to determine if community-based drop-in centres are effective in supporting women to breastfeed in populations where breastfeeding rates are low.

\section{Acknowledgements}

We gratefully acknowledge the Department of Education and Early Childhood Development, Victoria, Australia for funding SILC. We thank Dr. Heather McKay for her contribution to trial co-ordination (maternity leave replacement July 2012-March 2013), Ms. Anita Moorhead for her assistance with SILC-MCHN training, and Dr. Lyndsey Watson for her input into the statistical aspects of the SILC RCT. Thank-you to the women who assisted in piloting the initial documentation, the SILC-MCHNs, the municipality MCH teams, IT staff in all SILC LGAs who facilitated data collection and the women who responded to the SILC survey. We also thank members of the SILC Advisory Group and the Municipal Association of Victoria for their input and advice.

\section{Funding}

This study was funded by the Department of Education and Early Childhood Development, Victoria, Australia. The funders had no role in interpretation of data, or writing of the manuscript, and the views expressed in the manuscript are those of the authors and do not reflect the views of the funders.

\section{Availability of data and materials}

The ethics approval obtained for this study does not permit data collected in the study to be made available to anyone except the named investigators.

\section{Authors' contributions}

The study was conceived by HLM, DAF, RS and LHA. The study was designed in collaboration with all authors. RLC, HLM, DAF and TS constructed and pilot-tested the focus group schedules, SILC-MCHN survey and the semi-structured interview questions. All authors reviewed and approved the final focus group schedules, SILC-MCHN survey and the semi-structured interview questions. MC, TS and RLC collected and entered all data into the databases. RLC transcribed verbatim the digital audio files from the focus groups and interviews. RLC shared the main responsibility for statistical analyses with DAF and TS. Qualitative data analysis was undertaken independently by RLC and HLM. RLC drafted the manuscript with HLM, DAF and TS. All authors read and approved the final manuscript.

\section{Ethics approval and consent to participate}

The SILC trial received ethics approval from the Department of Education and Early Childhood Development (DEECD) (project number 2011_001305) and La Trobe University Human Ethics (project number 11-068) Committees.

\section{Consent for publication}

Written consent was obtained from all participants in this study, including explicit consent for publication of images included in this manuscript.

Competing interests

The authors declare they have no competing interests.

\section{Publisher's Note}

Springer Nature remains neutral with regard to jurisdictional claims in published maps and institutional affiliations. 


\section{Author details}

'Judith Lumley Centre (formerly Mother and Child Health Research), La Trobe University, 215 Franklin St, Melbourne, VIC 3000, Australia. ${ }^{2}$ School of Nursing, Midwifery and Healthcare, Federation University Australia, University Drive, Mount Helen, Ballarat, VIC 3350, Australia. ${ }^{3}$ School of Nursing \& Midwifery, La Trobe University, Bundoora, VIC 3086, Australia. ${ }^{4}$ Department of Women's and Children's Health, Karolinska Institutet, Retzius väg 13A, Stockholm, Sweden. ${ }^{5}$ The Royal Women's Hospital, Cnr Grattan St and Flemington Rd, Parkville, VIC 3052, Australia.

\section{Received: 17 July 2017 Accepted: 17 October 2017} Published online: 13 November 2017

\section{References}

1. Australian Institute of Health and Welfare (AlHW). 2011. 2010 Australian National Infant Feeding Survey: Indicator Results. Cat. no. PHE 156. Canberra: AlHW. http://www.aihw.gov.au/publication-detail/?id=10737420927. Accessed 1 Feb 2017.

2. Amir LH, Donath SM. Socioeconomic status and rates of breastfeeding in Australia: evidence from three recent national health surveys. Medical Journal of Australia. 2008;189(5):254-6.

3. Victorian Government Department of Education and Training (DET). 2015. Maternal and Child Health Services Annual Report (North-Western Victoria Region) 2014-2015, DET. http://www.education.vic.gov.au/Documents/childhood/ providers/support/2014-15\%20North\%20Western\%20Victoria\%20Region.pdf. Accessed 1 Feb 2017.

4. Victorian Government Department of Education and Training (DET). 2015. Maternal and Child Health Services Annual Report (South-Eastern Victoria Region) 2014-2015, DET. http://www.education.vic.gov.au/Documents/childhood/ providers/support/2014-15\%20South\%20Eastern\%20Victoria\%20Region.pdf. Accessed 1 Feb 2017

5. McLachlan HL, Forster DA, Amir LH, Small R, Cullinane M, Watson LF, et al. Supporting breastfeeding In Local Communities (SILC): protocol for a cluster randomised controlled trial. BMC Pregnancy and Childbirth. 2014;14:346.

6. McLachlan HL, Forster DA, Amir LH, Cullinane M, Shafiei T, Watson LF, et al. Supporting breastfeeding In Local Communities (SILC) in Victoria, Australia: a cluster randomised controlled trial. BMJ Open. 2016;6(2):e008292.

7. Ridgway L, Cramer RL, McLachlan HL, Forster DA, Cullinane M, Shafiei T, et al. Breastfeeding support in the early postpartum: Content of home visits in the SILC trial. Birth. 2016;43(4):303-12.

8. Amir LH, Forster DA, McLachlan HL, Moorhead AM, Chamberlain CR, McKay HJ. Breastfeeding in Victoria: A Report. Mother \& Child Health Research, La Trobe University. 2010. http://www.education.vic.gov.au/Documents/ childhood/professionals/health/breastfeedvic.pdf. Accessed 1 Feb 2017.

9. Oakley LL, Henderson J, Redshaw M, Quigley MA. The role of support and other factors in early breastfeeding cessation: an analysis of data from a maternity survey in England. BMC Pregnancy and Childbirth. 2014;14:88.

10. Schmied V, Beake S, Sheehan A, McCourt C, Dykes F. Women's perceptions and experiences of breastfeeding support: A metasynthesis. Birth. 2011;38(1):49-60.

11. Sudfeld CR, Fawzi WW, Lahariya C. Peer support and exclusive breastfeeding duration in low and middle-income countries: a systematic review and meta-analysis. PLOS ONE. 2012;7(9):e45143.

12. Kaunonen M, Hannula L, Tarkka MT. A systematic review of peer support interventions for breastfeeding. Journal of Clinical Nursing. 2012;21(13-14):1943-54

13. Jolly K, Ingram L, Khan KS, Deeks JJ, Freemantle N, MacArthur C. Systematic review of peer support for breastfeeding continuation: metaregression analysis of the effect of setting, intensity, and timing. BMJ. 2012;344:d8287.

14. Berridge K, McFadden K, Abayomi J, Topping J. Views of breastfeeding difficulties among drop-in-clinic attendees. Maternal \& Child Nutrition. 2005;1(4):250-62.

15. Adams $C$, Berger R, Conning P, Cruikshank L, Doré K. Breastfeeding trends at a community breastfeeding center: an evaluative survey. Journal of Obstetric, Gynecologic \& Neonatal Nursing. 2001;30(4):392-400.

16. Caddy R. The Reading breastfeeding drop-in centre. The Practising Midwife. 2002;5(10):18-22.

17. Pastore MT, Nelson A. A breastfeeding drop-in center survey evaluation. Journal of Human Lactation. 1997;13(4):291-8.

18. Stefiuk W, Green KL, Turnell R, Smith B. Process evaluation of the Saskatoon breastfeeding center. Journal of Human Lactation. 2002;18(1):29-37.
19. Fox R, McMullen S, Newburn M. UK women's experiences of breastfeeding and additional breastfeeding support: a qualitative study of Baby Café services. BMC Pregnancy and Childbirth. 2015;15:147.

20. Price L. Can early breastfeeding support increase the $6-8$ week breastfeeding prevalence rate? Community Practitioner. 2014;87(5):30-3.

21. Carswell A. Birthways Lactation Services: A model for breastfeeding support. Journal of Obstetric, Gynecologic, \& Neonatal Nursing. 2012. 41 (s1):S36-S36.

22. Forster D, McLachlan H, Lumley J. Factors associated with continuing to feed any breast milk at six months postpartum in a group of Australian women. International Breastfeeding Journal. 2006;1:18.

23. Avery A, Zimmermann K, Underwood PW, Magnus JH. Confident commitment is a key factor for sustained breastfeeding. Birth. 2009;36(2):141-8.

24. Carr S, Goldberg DJ, Elliott L, Green S, Mackie C, Gruer L. In practice. A primary health care service for Glasgow street sex workers: 6 years experience of the "Drop-in Centre", 1989-1994. AIDS Care. 1996;8(4): 489-97.

25. Mansey J. Setting up a nurse-led contraceptive clinic for young parents. Nursing Times. 2009;105(11):12-4.

26. Ingram J, Salmon D. 'No worries!': Young people's experiences of nurse-led drop-in sexual health services in South West England. Journal of Research in Nursing. 2007;12(4):305-15.

27. Kain K. Successful introduction of a community-based HIV service. Primary Health Care. 2009;19(7):22-4.

28. Souza R, Porten K, Nicholas S, Grais R. Outcomes for street children and youth under multidisciplinary care in a drop-in centre in Tegucigalpa. Honduras. International Journal of Social Psychiatry. 2011;57(6):619-26.

29. Magee C, Huriaux E. Ladies' night: Evaluating a drop-in programme for homeless and marginally housed women in San Francisco's mission district. International Journal of Drug Policy. 2007;19(2):113-21.

30. Richardson-Todd B. Setting up a nurse-run young person's drop-in clinic. Nursing Standard. 2003;17(47):38-41.

31. Ingram J, Salmon D. Young people's use and views of a school-based sexual health drop-in service in areas of high deprivation. Health Education Journal. 2010;69:227-35.

32. Osborne N. Children's voices: Evaluation of a school drop-in health clinic. Community Practitioner. 2000;73(3):516-8.

33. Wagget J, Robinson $\mathrm{H}$. Health drop-in for young asylum seekers. Practice Nurse. 2006;31(1):15-7.

34. Clinton D, Almlöf L, Lindström S, Manneberg M, Vestin L. Drop-in access to specialist services for eating disorders: A qualitative study of patient experiences. Eating Disorders. 2014;22(4):279-91.

35. Robson D, Cole F, Jalasi S, Boojharut B, Smith S, Thompson S, et al. Smoking cessation and serious mental illness: a service evaluation of a drop-in stop smoking clinic on an acute in-patient unit. Journal of Clinical Nursing. 2013;22(3/4):405-13.

36. Bauld L, Ferguson J, McEwen A, Hiscock R. Evaluation of a drop-in rollinggroup model of support to stop smoking. Addiction. 2012;107(9):1687-95.

37. Zhang L, Chen X, Zheng J, Zhao J, Jing J, Zhang J, et al. Ability to access community-based needle-syringe programs and injecting behaviors among drug users: a cross-sectional study in Hunan Province. China. Harm Reduction Journal. 2013;10:8-13.

38. Consultative Council on Obstetric and Paediatric Mortality and Morbidity 2014, 2010 and 2011, Victoria's Mother's and Babies: Victoria's Maternal, Perinatal, Child and Adolescent Mortality. State Government of Victoria: Melbourne. https://www2.health.vic.gov.au/about/publications/ researchandreports/Victorias\%20Mothers\%20and\%20Babies\%20Victorias\% 20Maternal\%20Perinatal\%20Child\%20and\%20Adolescent\%20Mortality\% 2020102011. Accessed 1 Feb 2017.

39. State Government of Victoria: Department of Education and Training. Maternal and Child Health Service. http://www.education.vic.gov.au/childhood/ professionals/health/Pages/maternalchildhealth.aspx. Accessed 1 Feb 2017.

40. Fox R, Mcmullen S. Report on Baby Café Services during 2014. The National Childbirth Trust. 2015. http://www.thebabycafe.org/set-up-a-baby-cafe/129annual-reports.html. Accessed 1 Feb 2017.

41. Attride-Stirling J. Thematic networks: an analytic tool for qualitative research Qualitative Research. 2001;1(3):385-405.

42. Green J, Thorogood N. Chapter 8: Beginning data analysis. In: Qualitative Methods for Health Research. 3rd ed. London: Sage Publications; 2014. p. 203-32. 
43. StataCorp. Stata Statistical Software: Release 11. College Station. TX: StataCorp LP; 2013. p. 2009.

44. Department of Education and Early Childhood Development. Maternal \& Child Health Services Annual Report 2011-2012. 2012. http://www. education.vic.gov.au/Documents/childhood/providers/support/report12.pdf. Accessed 1 Feb 2017.

45. Colchamiro R, Edwards RA, Nordstrom C, Eshelman J, Ghiringhelli K, Forgit J, et al. Mobilizing community resources to enhance postdischarge support for breastfeeding in Massachusetts (USA). Journal of Human Lactation. 2015;31(4):631-40.

46. Morris MR. Social networking site use by mothers of young children. Proceedings of the 17th ACM conference on Computer supported cooperative work \& social computing. Baltimore, Maryland, USA: ACM; 2014: 1272-1282.

47. McDaniel BT, Coyne SM, Holmes EK. New mothers and media use: Associations between blogging, social networking, and maternal well-being. Maternal and Child Health Journal. 2012;16:1509-17.

48. Bartholomew MK, Schoppe-Sullivan SJ, Glassman M, Dush CMK, Sullivan JM. New parents' Facebook use at the transition to parenthood. Family Relations. 2012;61(3):455-69.

49. Cramer RL, McLachlan HL, Shafiei T, Amir LH, Cullinane M, Small R, Forster DA. Women's experiences of breastfeeding support during the Supporting breastfeeding In Local Communities (SILC) cluster randomised controlled trial. Unpublished manuscript.

50. Hauck YL. Factors influencing mothers' decision to breastfeed in public. Breastfeeding Review. 2004;12:15-23.

51. Forster DA, McLachlan HL. Women's views and experiences of breast feeding: positive, negative or just good for the baby? Midwifery. 2010;26(1):116-25.

52. Scott JA, Mostyn T. Women's experiences of breastfeeding in a bottle-feeding culture. Journal of Human Lactation. 2003;19:270-7.

\section{Submit your next manuscript to BioMed Central and we will help you at every step:}

- We accept pre-submission inquiries

- Our selector tool helps you to find the most relevant journal

- We provide round the clock customer support

- Convenient online submission

- Thorough peer review

- Inclusion in PubMed and all major indexing services

- Maximum visibility for your research

Submit your manuscript at www.biomedcentral.com/submit 